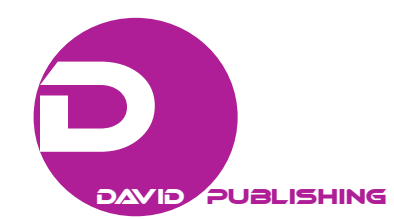

\title{
Profile of the Bulgarian Emigrant in the International Labour Migration
}

\author{
Magdalena Bonev \\ University of National and World Economy, Sofia, Bulgaria
}

\begin{abstract}
The current paper presents information about the Bulgarian emigrants and their characteristics. The data provided from Bulgaria about its emigrants are very limited, but the current work is aiming to present the details in the best way possible, so we can have a look at the specific flows of the emigration. The width, the length, and the periods of travel are described taking into consideration the data presented by Bulgaria as a sending country and some of the preferred destination countries. The examined data provided diversification between the aims of the potential permanent and potential temporary emigrants. The aging population of Bulgaria led us to the conclusion that we should have a further research on the structure of the emigrants, their age, sex, and occupation. According to the statistics we examined, Bulgaria exports mainly to young people, participants in the labour market. Many of them are students or people with primary education. One other share of them is presented by people, working in the production sector and having routine functions. The paper reveals also the socio-economic and material status in the determination of migrating for the labour emigrants from Bulgaria.
\end{abstract}

Keywords: Bulgarian emigrant, reasons to emigrate, socio-economic and material status of the emigrants

\section{Introduction}

Due to the specific features of Bulgaria's historical and socio-economic development, external migration is generally associated with the emigration of the population. Considering the 40-year ban on the free movement of people across the borders of Bulgaria, after the fall of the communist regime after 1989, there is a huge initial emigration wave, which is diminishing in the following years. The first wave of emigration is mainly of a political and ethnic nature, but shortly thereafter the departure of citizens begins to be determined by conditions and factors that increasingly caused an economic impact.

Before examining the main trends and status of the labour emigration from Bulgaria, we should have in mind the lack of sufficiently comprehensive and representative information on migration flows. In Bulgaria there is no system for registration, monitoring and reporting of the emigrants. However, using the available official statistics and indicators referring to the tendency of Bulgarians to emigrate, we can present as fully as possible the current state and place of Bulgaria in international labour migration.

\section{Emigration Structure}

As we stated above, the information about the Bulgarian labour emigrants is in many cases conditional

Magdalena Bonev, Ph.D., University of National and World Economy, Sofia, Bulgaria.

Correspondence concerning this article should be addressed to Magdalena Bonev, Miggaziplatz 5/32, Vienna 1120, Austria. 
and that is the reason why we looked for statistics provided by receiving countries. Statistics for the period 2010-2017 show that Bulgaria is a country with net emigration. For the last seven years, a total of 193,871 people left the country, with a significant part of them being well-educated and young people representing part of the working force. Unfortunately, there is a high chance that the data presented are in fact underestimated, and that Bulgarian emigrants are a lot more. Taking into account the migration statistics of host countries, this assumption is confirmed. Data for the population of Germany by country of origin, for example, show that in 2016 the Bulgarians were 262,320 and in 2017 they have increased to 310,415. This is an increase of more than 48,000 people or $15 \%$ in just one year. If we analyse the available data in the Austrian National Statistics, we can see that from 2002 to 2017 the Bulgarian population tends to increase and by only 7,601 in 2002 it reaches 25,686 in 2017. Data include all Bulgarians with current proof of address, as well as the ones that posses permit for permanent residence in the country and do not include short-term visit in the country within 90 days, as well as those staying illegally. We can conclude that the total number of emigrants could be even greater. According to the Bulgarian National Statistical Institute for 2017, a total of 26,992 people with Bulgarian citizenship have emigrated from the country-a figure even smaller than the displaced Bulgarians in Germany $(47,095)$, excluding other countries. Such huge differences can only be explained with the fact that the Bulgarian database contains information only for those who have declared to the administrative authorities a change of their current address from the country abroad.

The official Bulgarian statistics show that Bulgarians who have left the country over the past three decades are around 900,000, with nearly half of them (461,000) migrated between 1985 and 1992 within the "Big Excursion” or a forced exile of Bulgarians of Turkish descent during the communist regime. Considering the type of it, this part of the emigration of Bulgaria cannot be related to economic reasons and can be accounted as an occupational one.

However, data from foreign statistics indicate a higher total of emigration for Bulgaria, between 1.5 and 2 million people. After the transition to market economy, Bulgarian emigration is directed mainly to three destinations, Germany, USA, and Canada. Gradually, the economic environment in the country, especially since 2004, has improved. Foreign direct investment is entering the country, with a total of 36.99 billion euros in the period 1996-2009 and the economic growth is positive in 2008 and before the global economic recession reach $6.2 \%$. Unemployment in the country shrinks to $6.3 \%$ and the incomes of the population are rising. The overall macroeconomic status in Bulgaria directly affects the emigration attitudes of the population. It should state that with the non-visa travel to the EU, the motivation of potential migrants for seasonal migration also increased. The opportunities for temporary mobility provoke many Bulgarian citizens, especially those with lower skills, to seek seasonal work abroad. According to a number of studies, Germany is still among the most preferred economies, and the second place is took by United States. In 2016, Bulgarians were recorded over 300,000 or $31 \%$ in the European host country of the total number of emigrants, and 290,000 were reported in America. Preferred destinations for seasonal employment are Greece, Spain, Great Britain, and Italy. A serious segment of total Bulgarian labour migration in Greece and Cyprus is precisely the temporary occupation in the summer season. Greece is dominated by women who work as babysitters, housekeepers, or participate in the tourism. In Spain, the sexes are almost flattened as part of the women there arrive after their husband and don't take part of the labour market but take care of the household. 
The average length of emigration is about three to four years-different factors affect the decision on the period. Among them, the most important are: work opportunities in the host country, economic situation in Bulgaria, family and health reasons.

\section{The Bulgarian Emigrants' Structure Determined by Age and Gender}

Another important factor, which is influencing negatively the social and labour market development during the studied period, is the demographic factor. The demographic trends present a stable long downturn tendency and clearly outline the decreasing inflows in the labour market and aging of the Bulgaria population. The aging of the population in Bulgaria, as in many European countries, presupposes changes in the labour force structure in mid and long foreseen period, as well as changes in the pattern of consumption and public services. The gender distribution of Bulgarian citizens leaving the country is presented as a relatively stable trend for the period under review, apart from two years - 2010, when the men's emigration reaches 55\% and 2014, when the opposite effect appears and the women's emigration hits 55\%, we can state that equal part of the gender leaves the country of origin. Another perspective is the fact in many cases people emigrate with their family, that will mean, not only that a man or a woman are leaving the country but also that an entire household is emigrating.

In the years after the economic crisis, when the economy is still at a low growth rate and there is an unclear future perspective, one of the reasons why a large number of people emigrate is their pessimistic expectations that the economic, social, and institutional environment in Bulgaria will not improve significantly over a foreseeable period of time. Even though, the country does not generate high rates of emigration, as is the case with Romania, this process is extremely unfavorable to the demographic structure of the sending country. The forecasts for the development of the permanent population, calculated by the NSI, allow the trend to keep decreasing and in 2020 the permanent population is going to decrease by 3\% compared to 2015, 2040 by 14\% compared to 2015 and 2070 by 28\% compared to 2015, reaching five million and 123 thousand.

One of the main challenges facing Bulgaria is not just the growing emigration, but the fact that it is predominantly of young people of working age. This means the labour market will continue to lack of working force. The vast majority of Bulgaria's external migration is between the ages of 15 and 64 . Between 2010 and 2017, the population of working age is mostly over $85 \%$ of the total emigration, unfortunately, in 2017 it is reaching $93 \%$ (27,872 out of a total of 30,010 emigrants who left the country). The predominant part of the working emigrant population is up to 35 years old, and the tendency here is to increase the share of people between 15 and 35 years of age. At the beginning of the period under examination, emigrants up to 35 years old accounted for 46\% of the total number of working Bulgarians abroad, while in 2017 their share increased by 13 percentage points and reached $59 \%$.

Data from a sociological survey show that for "migrants" the main goal is "to live and work in a higher living standard" $-54 \%$, which in their opinion is provided or it is easier to achieve in the most desirable countries of emigration. For every fifth Bulgarian emigration is related to the solution of their own or family problems. The described emigrant is not able to operate a normal budget cycle. In many cases, we can conclude that this will be related to lack of personal skills, but also the lack of well-paid job offers can be assigned as another main factor. The main reason for leaving the country is the shortage of funds for family support-most immigrants are not unemployed when deciding to emigrate. This is helping them realise their intentions because they can afford to travel and stay until finding a job in the host country. On the other hand, some of the 
emigrants won't be able to provide a specific explanation of the question why would leave the country. Their answer is "I do not want to live anymore in Bulgaria". Obtaining desirable education for them or their children motivates $5 \%$ of emigrated Bulgarian citizens to relocate abroad. Among the temporary emigrants, which are seasonally employed in the receiving countries, the share of those who connect their residence abroad with the solution of material problems is predominant (47\%), while the aim of higher standard of living is generally $33 \%$. The Bulgarian emigrant citizens, whether those who already settled away, the potential or the temporary ones, have the confidence that going "abroad" will realise their intentions and goals. Interesting fact is that, despite of the goals they want to achieve through emigration, a significant part of Bulgarian emigrants is not aware of exactly how they would they achieve them from economic point of view. Great part of the Bulgarians is not prepared for their further employment and actions abroad and they represent about $40 \%$ of those who have left. The next share presented is of those who intend to do crafts-16\%. 9\% are geared to agricultural activity and 5\% are aiming to work in the area of trade and hotels. Surprisingly only $6 \%$ is the share of Bulgarians who are intending to continue their education and want to improve their qualification.

\section{Educational Structure of Bulgarian Emigration}

Contrary to widespread public opinion, emigration is predominantly composed of people with secondary and professional education. Among the reasons for this are the strong emigrational social connections. The societies of emigrants abroad provide to each other information and support, and therefore there is no need for significant additional knowledge or advanced university degree in general. Another reason is the fact that not a small part of the Bulgarians' crossed the state border at the beginning work in the informal economy of the host country. We should state that the employment in agriculture, trade, hotels and restaurants, construction and services is representing the opportunity for many emigrants for informal labour in southern Europe. This makes these sectors become the main places for illegal work. For university graduates, the intensity of emigration is between $6 \%$ and $8 \%$. Education as a reason for emigration most often applies to young people with still low levels of education who want to improve their knowledge, skills, and qualifications. The highest intensity and coverage (41\%) are those who have completed primary education. The share of secondary education is slightly lower-almost $35 \%$. The people led by the idea to emigrate and continue their education abroad come to a $24 \%$ and they have higher education - a master's or a doctoral degree. Unfortunately, we should have in mind that the distribution of migrants who have claimed their purpose of achieving higher level of education should be accepted with some conditionality due to the lack of comprehensive and representative data for the country.

\section{Socio-economic and Material Status of the Labour Emigrants From Bulgaria}

The economic and social status of each person greatly determines the way and the overall standard of living. For many of the Bulgarians leaving their own country, exactly the standards of life and the materiality are determining their decision to emigrate. From a conducted sociological survey, we can conclude that the groups in the population who "cope" with most of the difficulties caused by the current economic conditions, are most likely to be a potential part of the emigration (Kalchev, 2002). From the same survey, we can claim that most of the labour migrants were employed in private companies in the country of origin, nearly $34 \%$. The second place in the range is the unemployed with $27 \%$ followed by the students, who take up to $18 \%$ of the Bulgarian emigration. The lowest share is represented by the people with occupation in the country or municipal government or organization-only $2 \%$. 
The estimated values for the potential permanent labour emigrants are more than interesting. The determination and attitude towards emigration is highest across the students and the unemployed population. At the next, lower levels of readiness to emigrate and pursue personal goals come the employees in the community service sector of occupation and employees working in private companies. In future, students will form the migration flows. We can assume that those who will join the flows working in the private or public organizations will also be young people.

Regarding the occupations and professional realisation, the desire for emigration is most pronounced among the machinery and equipment operators, public services, security, trade and skilled production and unskilled workers. The desire to migrate is currently the most common among people in the production sector with routine functions. They account for $16 \%$ and $10 \%$ respectively of the occupational structure of labour migrants. In all cases, the desire for emigration from Bulgaria is decreasing as the accumulated years of personal work experience are increasing. For those who have a work experience of up to five years, the decision to emigrate takes up to $14.2 \%$ of all those claiming to want to settle within another country. As one can easily guess, these are mostly young people. Two percentage points are fewer citizens with work experience between 5 and 15 years. In the structure of labour emigrants, the lowest share is occupied by Bulgarians with experience of over 25 years.

Nearly half (49\%) of potential emigrants and those who have already settled in another country claim their financial status as "average”. Only $8 \%$ of labour and potential emigrants determine their financial status as "better" than other people. From the above data, we can assume that the wage is one of the main reasons and essential motivation for the decision to emigrate from Bulgaria.

\section{Conclusion}

Even though the information provided in many cases can be determined as imperfect, we managed to form and elaborate the profile of the Bulgarian emigrant. As we presented above, the emigration rates have raised in the recent years and for sure made an impact in the sending country as well as they made impact in the receiving country. The most popular destinations for a long-term emigration of the Bulgarians abroad are Germany, USA, and Canada, on the other hand, the temporary emigrants choose Greece, Spain, UK, and Italy. Unfortunately, Bulgaria is suffering from the process of aging population in result of the main range of age of the people departing from it (15-35 years old). More and more young people whether students or labourers are leaving the country, which is leaving negative impact on the country of origin, on the other hand, there are expectations of a better chances of development in Bulgaria with the right reform and regroup of the population. All the young people abroad returning in the sending country will be able to contribute to the local well-being of the population. Determined as temporary migrants, those societies support and invest in their better future in Bulgaria solve some of their financial issues or manage to improve their economical status compared to other citizens.

\section{References}

Kalchev, Y. (2002). Territorial mobility of the population. Sofia: NSI, 6/3, p. 67.

Kostadinova, S. (2007). Bulgarian emigrants - more benefits than losses for Bulgaria. Retrieved from http://www.ime.bg

Mihailov, D., Mintchev, V., Boshnakov, V., Nikolova, K., Petkova, K., Budgeva, R., Petrova, N., \& Ankov, B. (2007). Family patterns and migration. National representative survey. Project No. BUL1P201. Ministry of Labor and Social Policy and the United Nations Population Fund. 
Mintchev, V. (2007). Potential emigration from Bulgaria after 2007: Some new empirical evidences. Institute of Economics at the Bulgarian Academy of Sciences, Centre for Comparative Studies Sofia, Bulgaria.

National Statistical Institute, Bulgaria. (2017). Retrieved from http://www.nsi.bg/en

STATISTIK AUSTRIA Statistik des Bevölkerungsstandes. (2017). Retrieved from https://www.statistik.at/web_de/statistiken/me nschen_und_gesellschaft/bevoelkerung/volkszaehlungen_registerzaehlungen_abgestimmte_erwerbsstatistik/bevoelkerungsst and/index.html

US Census Bureau 2016 American Community Surveys Office for National Statistic. (2017). Retrieved from https://www.census. gov/acs/www/data/data-tables-and-tools/ 